\title{
Could Behavioural Nudges Improve the Accuracy of Waste Sorting? An Experimental Survey
}

\author{
D. I. J. Samaranayake ${ }^{1} \&$ R. S. Thennakoon ${ }^{1}$ \\ ${ }^{1}$ Department of Management Studies, Faculty of Management, University of Peradeniya, Sri Lanka \\ Correspondence: D. I. J. Samaranayake, Department of Management Studies, Faculty of Management, University \\ of Peradeniya, Sri Lanka. Tel: 94-712-919-780. E-mail: dijs@pdn.ac.lk
}

\author{
Received: December 7, 2020 \\ Accepted: January 4, $2021 \quad$ Online Published: January 6, 2021 \\ doi:10.5539/ep.v10n1p1 \\ URL: https://doi.org/10.5539/ep.v10n1p1
}

\begin{abstract}
The study consisted of a survey and field experiment to observe the impact of behavioural nudges on an individual's attitudes and accuracy on waste sorting. The survey conducted on 203 students of the University of Peradeniya, and then the field experiment within the university premises. The responses to the survey revealed that the participants having a negative attitude toward the usual waste disposal and sorting practices. Also, the majority of the respondents preferred non-monetary incentives as an effective strategy to motivate individuals to improve the accuracy of waste sorting. Then the participants are given nine strategies as separate behavioural nudges to improve the waste sorting behavior. The responses are highly varied and the majority prefer to use a combination of different colours and detailed labels as a motivational strategy. Thus, the preferred strategy was examined at the faculty premises throughout three stages and tested three hypotheses. Findings revealed that the strategy improves the accuracy, and supports the university community for proper waste sorting practices. Further, it exposed that the detail labels and stickers are impactful than the colour sensitivity of respondents.
\end{abstract}

Keywords: behavioural nudges, choice architecture, colour sensitivity, motivation, waste disposal, waste sorting

\section{Introduction}

\subsection{Background of the Study}

Waste generation increasing fast as the limits of population growth, urbanization, industrialization, and consumer behavior expanding over the decades. Thus, the waste generated upon human activities created ample challenges to future generations. According to recent statistics, waste generation only from global cities is about 1.3 billion tons. Estimated global waste generation lays around two billion tons with $0.74 \mathrm{~kg}$ per person by 2016 (WB, 2019). Also, it is above one million tons within the Asian region. According to Hoornweg \& Bhada-Tata (2012), the estimated global waste generation is expected to increase above three billion tons by 2025 , but it is almost reached by 2020. Also, global waste management costs hundreds of billions of USD. Thus, it is important to pay attention to the waste management practices globally, as well as locally to mitigate the environmental damage and also the financial loss we are expected to experience in near future.

When it comes to the Sri Lankan context, the collapse of the massive garbage dump at "Meethotamulla" in April 2017 shed red light on the future of waste management practices. This incident worsens the repercussions on the livelihoods at the affected areas as they were experiencing many difficulties in their regular life throughout the waste collected into the "Muthurajwela" and "Colombo Bluemendal" garbage dumps. Further, the animals who lived around the dumps had consumed waste and ample biological and digestive difficulties. As well as, groundwater pollution due to the dumps across the wetlands generated more hygiene-related health problems due to inappropriate waste disposal methods. Not only such environmental and health issues but also economically this problem gave negative results. At present many institutions have spent a lot of money on waste disposal mechanisms. However, as a result of the informal and unplanned waste sorting practices, the majority has to put enormous effort into waste disposal. Also, present waste disposal practices have not reflected modern technology as Sri Lana has practicing primitive waste disposal and sorting methods such as the use of garbage bins for disposal waste after separation, recycle, composting, etc. Also, such primitive methods are not properly implemented at the bottom level of waste management in Sri Lanka.

This study focuses this venture at the bottom level of waste management over a few equally important objectives. 
First to test the viability of usual practices in waste management and followed by a validity survey for the "Nudge theory". Then to perform a perception analysis on the waste disposal practices among the university community and finally to identify feasible "Nudges" to be used among the university community. This study is based on a key behavioral economic theory, "the Nudge theory" introduced by Richard Thaler, the Nobel Prize winner in 2017 for economic sciences. The theory introduced a strategy to architect choices without changing its financial returns as a new approach to motivate rather than using mandates or typical incentives. The methodology consists of a Framed Field Survey and a Natural Experiment. The Framed Field Survey used 203 respondents through five stages from both Arts and Management Faculties of the University of Peradeniya. Then the natural field experiment targeted students from both the faculties and placed the bins within the Faculty of Management to test three hypotheses. The hypotheses were tested through comparison across the photographic pieces of evidence from a baseline experiment and two treatments.

\subsection{The Problem of Waste Management and its Impact}

The waste management in the developing nations had some composite issues as improper wage sorting behaviours limit the range of selections in the management process. When it refers to the waste disposal methods, the common third world practices used to be landfilling and open dumping. However, it appears as a challenge for countries as it is not convenient to find suitable lands for the above purposes. As a result, the recent practices in open dumping showcased several issues as a variety of environmental, health, safety, and social issues experienced across the developing nations.

According to Alam \& Ahamade (2013), the Indian community faced multiple difficulties due to long term practice in open dumping. Toxic gasses produced from the open dumps are one of the severe issues and further the diseases and pollutions in water, air, and soil damages the well-being of livelihoods. Similarly, Ayub \& Saleem (2015) observed that improper landfills and open dumps in India led to massive pollution in groundwater and disturbs the hygiene of citizens. Further, they revealed that a considerable proposal of dumped waste is recyclable and the inadequate concerns in waste sorting at the bottom level let India face such difficulties when it comes to landfilling and open dumping. Also, it is important to consider the effect of financial and technological barriers on waste management in underdeveloped nations. Improper waste disposal practices in Zimbabwe and Burkina Faso reflected this situation. Zimbabwe has serious impacts on the livelihoods of its citizens due to the communicable diseases that emerge from the landfills and open dumps (Makwara \& Magudu, 2013). Also, the city of Kaya in Burkina Faso had faced troubles through water pollution due to the lack of financial and technological assistance in managing the waste sorting and disposal practices (Kafando et al., 2013).

When it comes to the composition of waste, it is important to consider the impact of the polyethylene verities on the environment and livelihoods of citizens. According to Durak (2016), the polyethylene verities embed in landfills and open dumps are a series of a threat to the lives in water, air, and soil. For instance, Tokyo city in Japan faced difficulties from polythene as crows around the city pollute the city by carrying the wasted polyethylene within the city (Kanai et al., 2003). Also, a study by Bandara \& Hettiarachhi (2003) identified the relevance of such difficulties in the Sri Lankan context. It verified that the landfills and open dumps tend to pollute the water, release toxic gases into the air, and reduce the value of properties situated around the dumps.

\subsection{Different Approaches to the Waste Management}

The process of waste management includes different stages such as collection, sorting, storing, transportation, and dumping the waste generated through human activities. Also, we can observe several socio-economic concerns such as different patterns in consumption, urbanize livelihoods, occupations, income levels, and other structural issues that have a close connection with the dynamics in the waste management practices in different countries. Proper waste management appears as an essential practice in the modern world as the growing population let the waste generation to increase over time, and any mismanagements as dumping unnecessary waste through improper recycling chain always create health issues as well as economic difficulties in aggregate sense (Lokhande \& Pawar, 2016).

Also, different countries have got different resources and technologies in observing solutions for the waste generated throughout the process of waste management. Open dumping, landfilling, composting, incineration, waste to energy, and 3R [Reduce, Re-use, Recycling] are some of the popular practices around the world. According to Paz (2006), most western countries use composting, incineration, recycling, and reducing the quantity of waste as their solid waste management practices. Also, they were recommended as the best practices for any economy across the world. According to the reports published by the Ministry of the Environment - Japan (2012), they were interested in incineration with the highest possible technology to reduce the volume of toxic gas that could produce through the process. Further, the German practices in waste management reflect proper sorting 
and then use them for composting and waste to energy generation processes (Herion et al., 2008). However, the technological barrier appeared as a crucial matter when the underdeveloped nations are in concerns of waste management through the best practices such as incineration, waste to energy generation, etc. (Kafando et al., 2013). According to Achankeng (2003), most of the poor and developing nations are still utilizing the basic waste management practices for a long time and they are not sustainable. For instance, waste management in African nations is depending on the reuse of non-recyclable materials, landfills, and open dumping. However, the United Nations Sustainable Health Programme - UNSHP (2010), introduced the " $3 \mathrm{R}$ Concept" for such nations to manage their waste through practicing Reduce, Recycle, and Re-use of the generated waste. Then a country must ensure the support by the bottom level of the waste generation process as proper sorting behaviour is highly important for the smooth functioning of the $3 \mathrm{R}$ concept in any country irrespective of its economic and technological strengths.

In the context of Asia, Aiza et al. (2007) proposed composting as an appropriate application as most Asian countries have a high volume of recyclable waste. On the other hand, they were not recommending waste to energy process. Similarly, Themelis (2003), had provided further explanations to the intention not to recommend waste to energy process to the countries with financial and technological challenges. This is supporting the idea that it is important to utilize domestic practices at the initial level of waste management rather than confer to the neediness of someone else technology at the bottom-line. Further, the importance of domestic practices on the waste management in Sri Lanka also highlighted, and recommend proper waste sorting practices at the bottom level and to compost them rather than dump everything in an inappropriate manner (Lekammudiyanse \& Gunathilake, 2009). On the other hand, such proper sorting practices can support recycling processes. However, the Sri Lankan recycling industry has not utilized improved technology in recycling processes and resulted in a considerable degree of environmental pollution by the existing recycling methods (Bandara et al., 2010). Also, Bandara \& Hettiarcchi (2003) stated that improper waste sorting behaviour generates difficulties in waste management practices and formulated several difficulties in landfilling and open dumping.

\subsection{Behavioural Nudges for Waste Management}

Motivation is a psychological process that could encourage any individual or entity to achieve their needs. According to Maslow (1943), a typical human being got five basic needs such as physiological needs, safety needs, love and belonging, esteem, and self-actualization in a hierarchical order. Any activity or effort made on fulfilling such basic needs would generate motivation (Pardee, 1990). Also, it is important to identify different types of motivational approaches such as orders, mandates, and incentives. Ariely et. al (2009) emphasized the importance of financial incentives as a motivational tool towards effective personalized achievements. However, it is important to consider the fact that motivation is not always driven by financial incentives, and many more factors and characteristics are required to concern (Prendergast, 2008). For instance, financial incentives are not responsive to pro-social motivation (Banuri \& Kafeer, 2016) as financial rewards are not motivating agents to exert extra effort during tasks embed a pro-social mission. Also, the degree of mission match between the agents has a significant impact on their motivation to complete the tasks (Carpenter \& Gong, 2016; Smith, 2016).

Then the importance of innovative approaches for motivation is highlighted as the behavioural characteristics of the individuals are not always described through the typical methods such as mandates and incentives. As a result of that, Thaler \& Sunstain (2009) came up with the idea of behavioural nudges as an innovative approach to motivation. The behavioural nudges are generally known as hidden alternatives that are not observable as the default choices for a given action or incident. Then a choice architecture does some arrangements to the venue where the action or incident take place to emphasize the hidden choice alternatives and they are the nudges. Such nudges can reduce the issues related to the decision-making process of individuals along with only the default options and status-quo bias. According to Heiskanen et al. (2014), behavioural nudges could lead human decisions towards a sustainable direction. It is an innovative motivational strategy that can lead people to choose better options for the wellbeing of themselves as well as the environment. However, it should be clear that the behavioural nudges are separated from financial incentives. The nudges could change the atmosphere of choices having the same incentive mechanisms and that could lead the individual to observe more options as choices to his/her intended action or decision (Ly, et al., 2013).

Further, Cooper (2017) highlighted the applicability of behavioural nudges in a variety of platforms such as improving the healthiness of people, preserving the environment and energy sources, transportation, etc. For instance, the studies by Kroese et al. (2015), Brooks (2015), and Anamaria et al. (ND) show how behavioural nudges could help people to spend a healthy life. Kroese et al. (2015) conducted a study to observe the impact of nudges on consumer's food preferences. Their findings revealed that a new arrangement for the same food varieties in a particular cafeteria can lead consumers to demand healthier foods. Also, a similar type of experiment conducted by Brooks (2015) to identify the significance of behavioural nudges in controlling alcohol consumption 
by the consumers. Anamaria et al. (ND) identified that behavioural nudges are important in improving the mineral water consumption of people to ensure a healthy lifestyle.

There is a significant number of experimental studies that focus on how behavioural nudges help in preserving environmental and energy sources. Cooper (2017), examined the approaches in reducing the adverse effects of climate change and global warming by changing the disastrous modes of human interactions with nature through behavioural nudges. Helgesen et al. (2015) observed how the behavioural nudges help reduce the household waste and to improve their motivation to recycle the existing waste. They experimented with the household behaviour in Kristiansand city, Norway, and found that the choice architects can make a significant impact on the respondent's attitude towards the reduction and recycling of household waste. Also, Liebig \& Rommel (2014) used a sticker which consisted of a behavioural nudge to motivate households to decline the environmental damage done by the unnecessary letters dumped around the letterboxes. The outcome of the experiment demonstrated how important behavioural nudges improve people's attitudes towards pro-environmental behaviour. Similarly, Macnabb (2017) observed the importance of nudging to improve environment-friendly behaviour. According to OECD (2017), multiple behavioural biases affect individual choices on waste generation, sorting, and recycling. Thus, a proper approach requires as waste sorting and recycling is hindered by unintimate designs of waste bins, etc.

The studies conducted by Ly et al. (2013) and Cosic et al. (2018) show how behavioural nudges are important in waste management with special concern towards the waste sorting and disposal behaviours. Ly et al. (2013) observed that the people's waste disposal behaviour can make more standardized through an innovative arrangement for the bins such as drawing attractive green footprints towards the waste disposal bins. Also, Cosic et al. (2018) observed that the size of the bin has a significant impact on the quality of waste sorting behaviour of the respondents. They put a larger bin for the recyclable items compared to other bins and attracted a high volume of recyclable waste throughout a proper sorting mechanism.

Further, recent reviews on waste management in Sri Lanka revealed that the majority of waste [around seventyfive percent] generated as kitchen waste, and even three fourth of the waste could be bio-degradable (WACS, 2014; Dharmasiri, 2020). This means the majority of waste tends to generate at the primary level, whereas the household behaviour impacts a lot, and a proper waste sorting practice can help to minimize the possible damages by improper practices embed in land-filling and open dumping. Also, it is important to consider behavioural applications on the waste sorting behaviour of individuals and to observe the applicability of behavioural nudges in improving the waste sorting practices in Sri Lanka. This would be an important review as we do not have a proper system or practice for waste separation at the generation or collection points (Dharmasiri, 2020). Even, it is important to think of a behavioural strategy to improve the waste management practices in Sri Lanka since we have less tendency to adopt advanced strategies. Thus, we consider primary methods such as composting, use of bins to separate waste, open dumping, etc. Accordingly, this study focuses this venture at the bottom level of waste management focusing on the waste sorting and disposal practices among the university community to identify feasible behavioural nudges and their implications.

\section{Method}

\subsection{The Conceptual Framework and the Flowchart of the Study}

The foremost objective of this study is to observe the applicability and ability of behavioural nudges to improve the waste sorting behaviour among the Sri Lankan citizens. Accordingly, the study used two equally important methods to identify waste sorting practices and to examine the validity of behavioural nudges. The following framework provides a brief path diagram for the intended analysis.

Framed field survey Natural field experiment

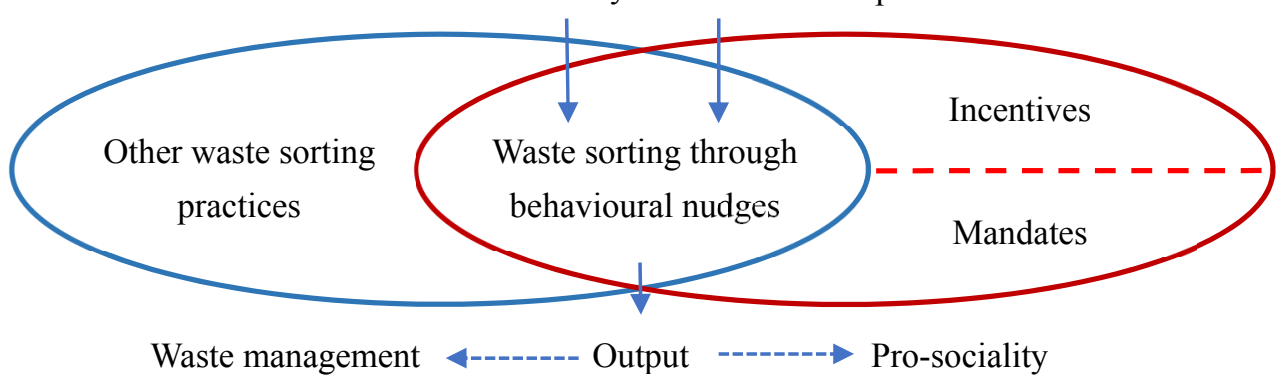

Figure 1. The conceptual framework 
As illustrated in figure 1, this study intends to utilize both the framed field survey and natural field experiment to observe the applicability of behavioural nudges in generating a positive impact on the waste sorting behaviour of individuals. Also, the outcome may have the capacity to improve the degree of prosocial motivation of individuals as a result of the moderated choices. Further, the flowchart of this study represented in figure 2, and demonstrate how we reached the experimental findings.

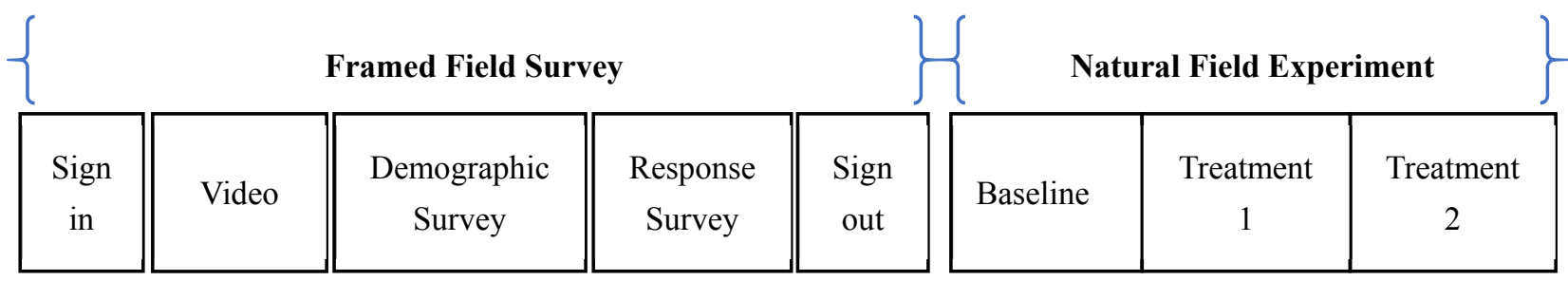

Figure 2. The flowchart of the study

Accordingly, the initial fraction of the study consisted of the framed field survey and the sessions are scheduled to play a video clip with some motivational tips to provide sufficient knowledge on the global and local issues related to waste management as well as the recent waste sorting practices in Sri Lanka. Then the demographic survey collects the respondent's information and then moves to the response survey. After the completion of all sessions of the framed field survey, an analysis of the data on respondents' preferences and perceptions on the waste sorting methods used as the criteria to decide the behavioural nudge for the natural field experiment. This experiment conducted within the university premises as respondents involved in the framed field survey is undergraduates. The experiment consists of a baseline [examine the waste sorting behaviour without nudge], and two treatments [examine the waste sorting behaviour having two different combinations of nudges].

\subsection{Structure of the Experiment and the Analytical Strategy}

The natural field experiments appear to be one of the most realistic and reliable investigations on the dynamics of human behaviour as both the internal and external validity of such observations are very high compared to the other methods. The experiment includes a baseline where the garbage bins are placed in the field without a nudge for a scheduled period. Then the first treatment [T1] applies the behavioural nudge observed from the responses on the survey and placed in the field for the same scheduled period. Thereafter, the second treatment [T2] offers some alternations to the same behavioural nudge applied at the first treatment and placed in the field for the same period. All the three sessions of this experiment were examined equally and use the photographic evidence of waste sorting behaviours across the baseline and treatment to observe the treatment effects.

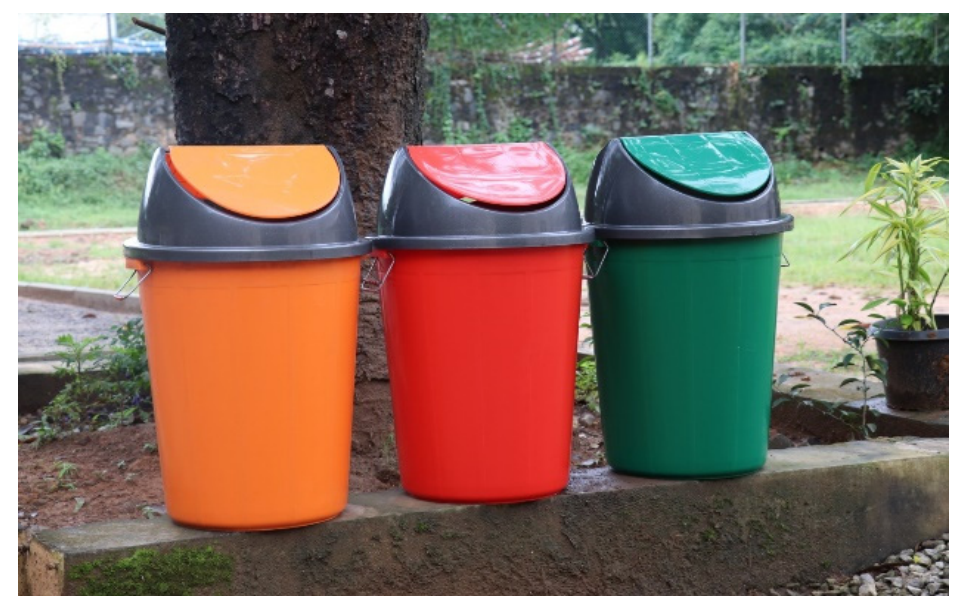

Figure 3. Garbage bins at the baseline of the experiment

Figure 3 shows the three colour bins used for the experiment and the baseline just represent three bins in three different colours like green for food waste, red for polythene and yellow for the paper wastes. Further, it is 
important to clarify that the experiment consisted of three hypotheses to test the treatment effects.

Hypothesis 1: Behavioural nudge generates a positive impact on waste sorting behaviour compared to the baseline.

Hypothesis 2: Behavioural nudge with alternations generates a positive impact on waste sorting behaviour compared to the baseline.

Hypothesis 3: Behavioural nudge generates a positive impact on waste sorting behaviour compared to the behavioural nudge with alternations.

The initial hypothesis (H1) distinguishes the performance of the nudged and non-nudged subjects. Then the following hypotheses $(\mathrm{H} 2 \& \mathrm{H} 3)$ consider the strengthen of nudging [do some alternations to check the power of nudge tool] compared to the baseline and standard nudge.

The study expected to use 208 undergraduate and postgraduate students from both the Faculty of Arts and Management for the framed field survey. The 208 respondents are randomly selected with an equal share of participants from each faculty. Finally, 203 responses [101 subjects from the Faculty of Arts and 102 from the Faculty of Management] were recorded for the analysis. All the framed field surveys are equally timed and the total time proposed for a survey is 20-30 minutes. The data analyzed through descriptive analytics with appropriate table and figures to express the outcomes. Then the natural field experiment targeted students from both the faculties and placed the bins within the Faculty of Management. Each placement consisting of the baseline and treatments are equally timed and the photographic evidence is used to measure the treatment effects.

\section{Results}

\subsection{The Framed Field Survey}

The data were collected from a pool of participants consisting of undergraduates and postgraduates of the University of Peradeniya. Figure 4 demonstrated the composition of the gender and age and the majority of the sample consisted of female undergraduate students between 21-23 years of age.
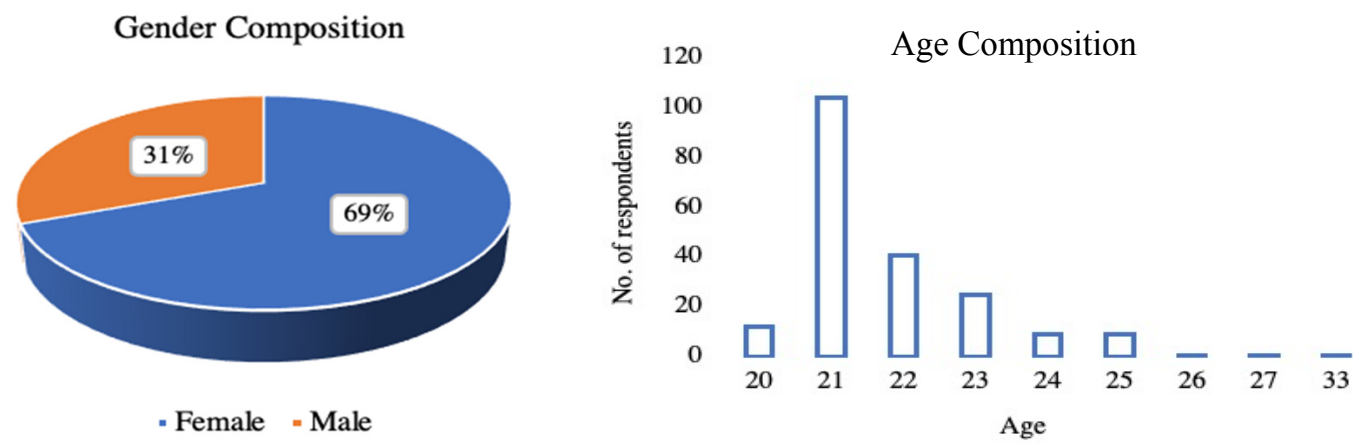

Figure 4. Gender composition of the subjects

Then the next phase of the survey collected the respondent's attitude towards the waste disposal methods. According to the responses provided in figure 5, the majority agree on the disposal of waste into the garbage bins, but still, around 22 percent of the respondents are not agreeing using bins as their primary method.

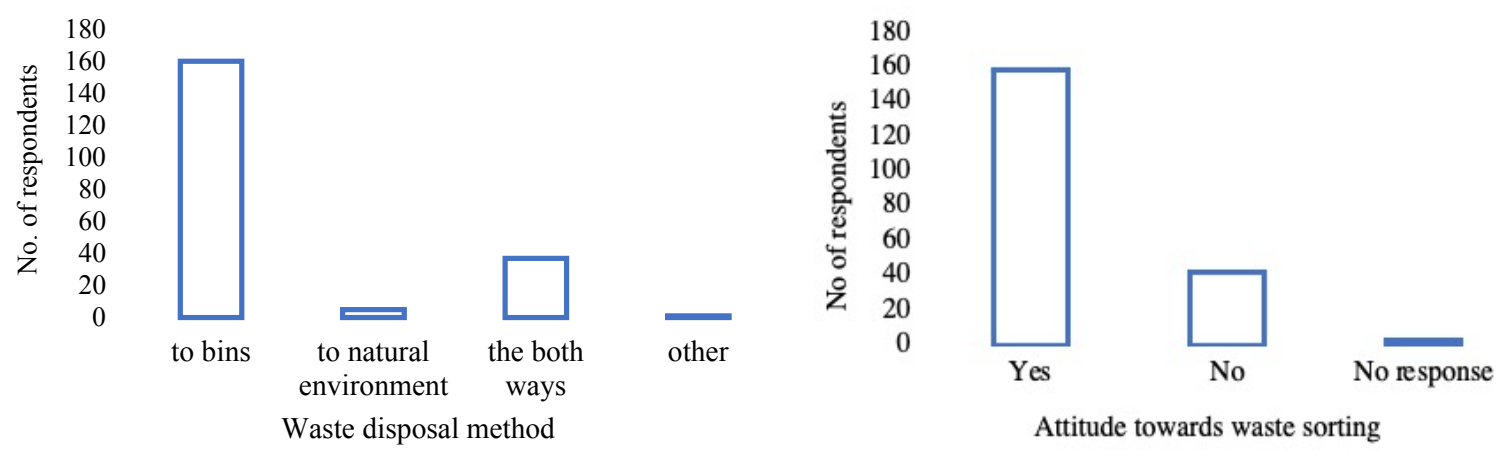

Figure 5. Attitude towards the waste disposal and sorting 
This provides us with the opportunity to observe how the respondents concern their simplest task as the next step in our observation to identify their attitude towards waste sorting. Since the majority prefer garbage bins to dispose of their waste, figure 5 shows how the respondent's attitudes vary across the waste sorting before the disposal. It demonstrates that the majority of respondents even prefer to separate waste before disposal in the bins. Thus, the responses from the sample demonstrated that around twenty percent of respondents were not concerned about the garbage bins as the best approach to dispose of the waste, and also not interested in waste sorting before the disposal. In addition to that, the survey includes another task for the respondents to verify the degree of attitude expressed by the above segments. Thus, figure 6, expressed how regularly the respondents tend to sort their waste as a day-to-day practice though they agreed upon waste sorting before disposing of it in the garbage bins.

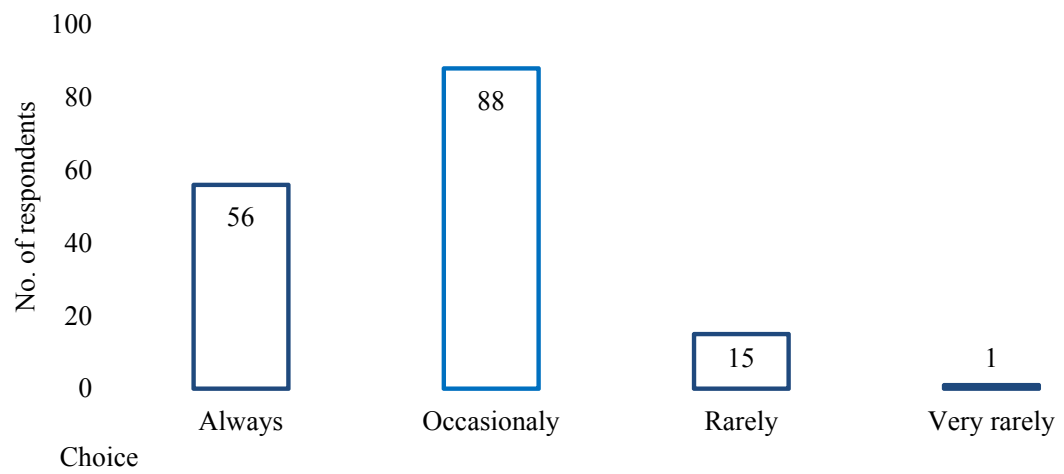

Figure 6. Dynamics in the waste sorting practices

The data reveals how frequently the subjects intend to sort the waste before disposing of it in the bins. The majority of the respondents tend to sort waste occasionally and it is 88 respondents out of the total who intend to sort and put waste into the bins. Also, about 56 respondents tend to sort waste always and represent that the waste sorting practices of the respondents are quite frequent in general. Then the next fraction of the survey let respondents provide their perception of the recent waste management practices in Sri Lanka. Accordingly, figure 7 demonstrated the respondents' perception of the quality and the effectiveness of waste management practices in Sri Lanka.

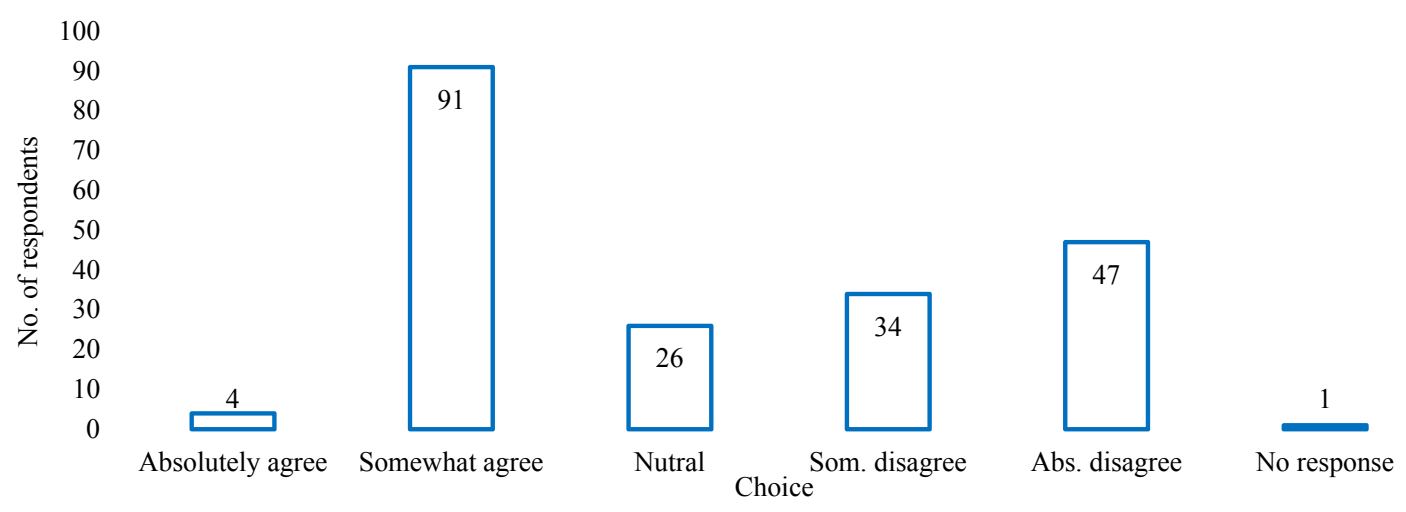

Figure 7. Perception on the quality of waste management practices in Sri Lanka

The majority of the respondents are somewhat agreeing on the standards of the waste management practices in Sri Lanka having only four respondents agree in total on the statement "I would agree with the quality of the waste management practices in Sri Lanka". On the other hand, forty-seven respondents have disagreed with this statement having thirty-four somewhat agree. This lets us think that a considerable proportion of the sample are not agreeing with the prevailing waste management practices in Sri Lanka. Further, we asked whether waste sorting before disposal is an effective practice in Sri Lanka.

According to figure 8 , it is clear that the majority [around 80 percent] of the respondents accept that waste sorting before the disposal is important. However, it is crucial to identify whether people practice waste sorting though 
they identified the importance of it. Thus, we let the respondents express their real-time experience on the waste sorting behaviour in Sri Lanka.

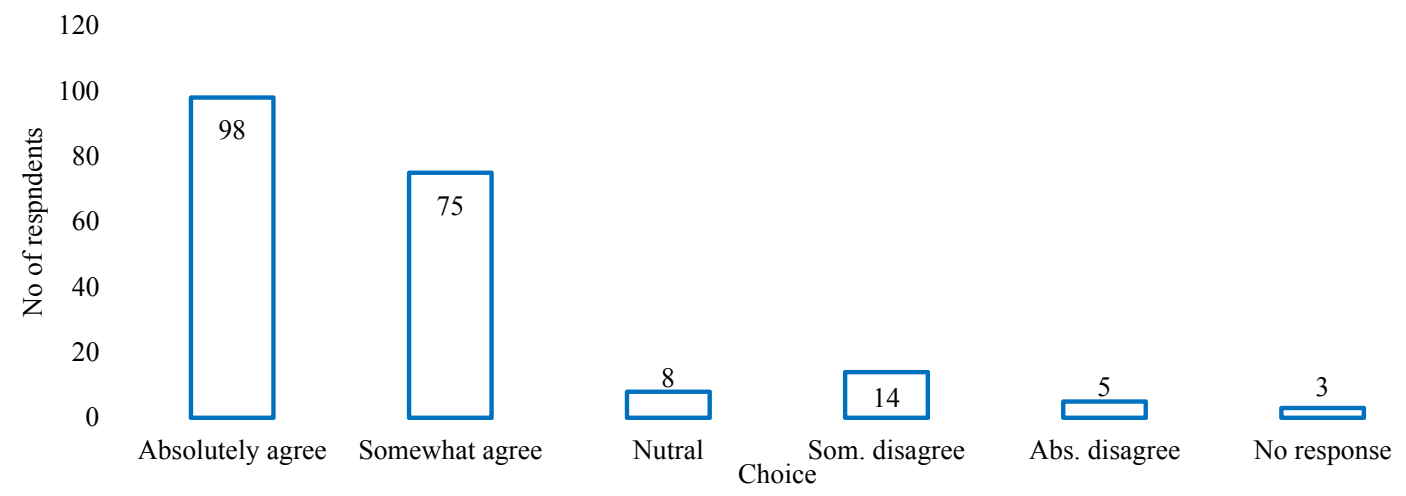

Figure 8. Perception on the importance of waste sorting before disposal

Figure 9 demonstrates how the respondents think of the potential of real-time waste sorting practices among Sri Lankan citizens. It clearly shows a majority [above 60 percent] of respondents are not agree on the prevalence of waste sorting practices among Sri Lankan citizens. This is where we have to focus as the behavioural nudges have greater potential to improve the people's attitudes and potential waste sorting as they know the importance of that particular activity.

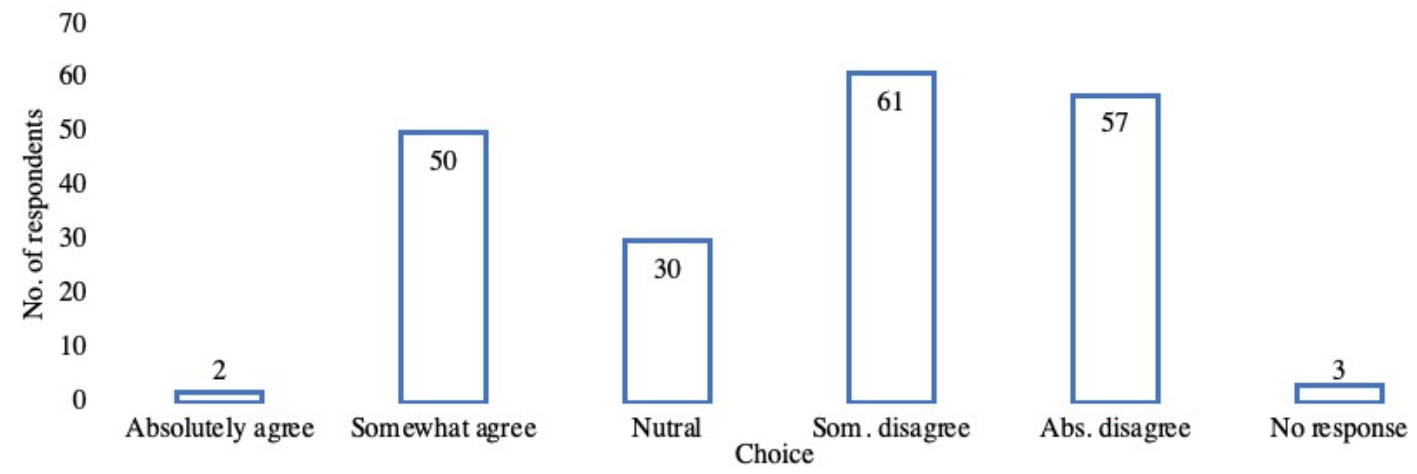

Figure 9. Perception on the waste sorting practice among the Sri Lankan Citizens

Then, the next fraction of the survey consisted of some questions to observe how the peoples' engagement in waste sorting behaviour can be improved. First, we asked the respondents to express their preferences on the use of traditional motivational methods to improve waste sorting practices.
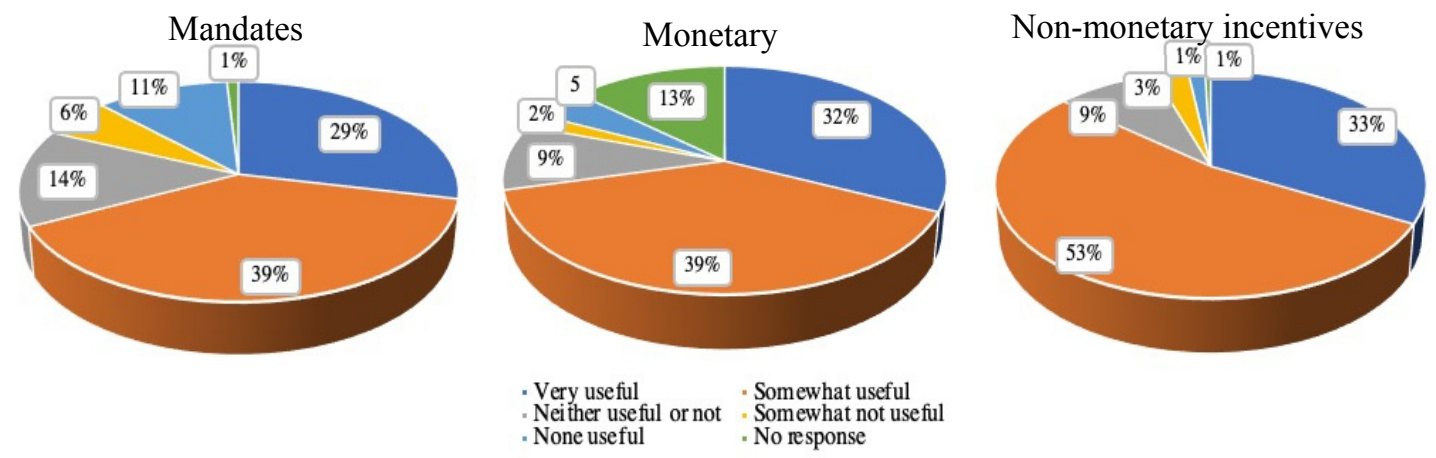

Figure 10. Importance of typical motivations to improve the waste sorting practices 
According to the survey, more than ninety percent of the respondents are agreed on motivating the public on waste sorting behaviour. Then we asked their preference for traditional motivations such as mandates and incentives. As demonstrated in figure 10, data clearly showed that only 39 percent of the respondents think both the mandates and monetary incentives are very useful in motivating the waste sorting behaviour. On the other hand, above 50 percent of respondents think non-monetary incentives are very useful for such purposes. It seems the majority of respondents are aware of the effectiveness of the traditional motivations and they have some faith in non-monetary incentives. Non-monetary incentives include a wider range of tools such as appreciations, acknowledgements, respect, provision of opportunities, physical rewards, and also the behavioural nudges.

However, the majority of respondents maybe not considering the nudges as a noon-monetary reward but still strongly believe they are powerful than the mandates and monetary rewards to motivate people for waste sorting prior disposal into the garbage bins. Then, our next set of questions let respondents go for the same kind of individual assessment by considering the importance of different nudge tool provided as strategies to motivate people for a proper waste sorting practice. For that purpose, we include nine types of nudges [see Appendix A for the list of nudge tools] and table 1 demonstrates a summary of the respondent's concerns on them.

Table 1. Respondent's preferences across the behavioural nudges

\begin{tabular}{ccccc}
\hline \multirow{2}{*}{ Nudge tool } & \multicolumn{3}{l}{ Waste sorting behaviour and the use of garbage bins } & \\
\cline { 2 - 5 } 1 & Will increase & Will remain the same & Will decrease & No response \\
\cline { 2 - 5 } 2 & $53 \%$ & $34 \%$ & $11 \%$ & $2 \%$ \\
3 & $\mathbf{6 5 \%}$ & $\mathbf{3 0 \%}$ & $\mathbf{4 \%}$ & $\mathbf{1 \%}$ \\
4 & $29 \%$ & $42 \%$ & $27 \%$ & $2 \%$ \\
5 & $39 \%$ & $47 \%$ & $10 \%$ & $4 \%$ \\
6 & $54 \%$ & $37 \%$ & $7 \%$ & $2 \%$ \\
7 & $43 \%$ & $26 \%$ & $28 \%$ & $3 \%$ \\
8 & $45 \%$ & $33 \%$ & $20 \%$ & $2 \%$ \\
9 & $39 \%$ & $32 \%$ & $28 \%$ & $1 \%$ \\
\end{tabular}

According to table 1, about 65 percent of the respondents believed in coloured bins classified with stickers [nudge tool 2] as the most effective nudge tool to motivate the waste sorting and use of bins for disposal. Also, above 50 percent of respondents agree with indicating paths with coloured footprints towards the bins [nudge tool 1] and use the symbols or pictures of different political parties to motivate people while separating them [nudge tool 5]. In contrast, the use of different sounds for different bins [nudge tool 3] is the least preferred option and the majority of the respondents do not expect any positive motivation towards the waste sorting and use of bins through that strategy. Also, the use of celebrities for different bins [nudge tool 4] and changing the shape or size of the bins [nudge tool 8] are two other least preferred strategies as only 39 percent of the respondents think of them as effective approaches. Thus, these responses show a significant variance across the nudge tools in terms of their effectiveness and it helps us to identify the nudge strategy to be utilized in the natural field experiment. We used coloured bins with name stickers as the nudge tool to examine the three hypotheses stated in section 3.2.

\subsection{Natural Field Experiment}

The study conducted the natural field experiment within the premises of the Faculty of Management, University of Peradeniya. The bins were placed in locations where the students from the Faculty of Arts and Management interact. Since, the most preferred nudge tool is the use of coloured bins classified with stickers, three hypotheses mentioned in section 3.2 can be modified as follows,

Hypothesis 1: Bins with colour and name sticker match generates a positive impact on the waste sorting behaviour compared to the baseline.

Hypothesis 2: Bins with colour and name sticker mismatch generates a positive impact on the waste sorting behaviour compared to the baseline.

Hypothesis 3: Bins with colour and name sticker match generates a positive impact on the waste sorting behaviour compared to the bins with colour and name sticker mismatch. 
The following are the comparison of the experimental outcomes across the baseline and the three treatments developed upon the hypotheses stated above. Photographic evidence uses as a tool for the comparison of the baseline and treatments through observing the types of waste disposed of in the garbage bins.

\subsubsection{Experimental evidence from the baseline [bins without name stickers]}

The baseline of the experiment consisted of three different bins to indicate the expected type of waste as the green colour for food waste, yellow colour for paper waste, and red colour for polyethylene materials. The figure shows the three bins in the baseline condition. Then the photographic evidence on the disposed waste is shown in figure 11 for the comparison.

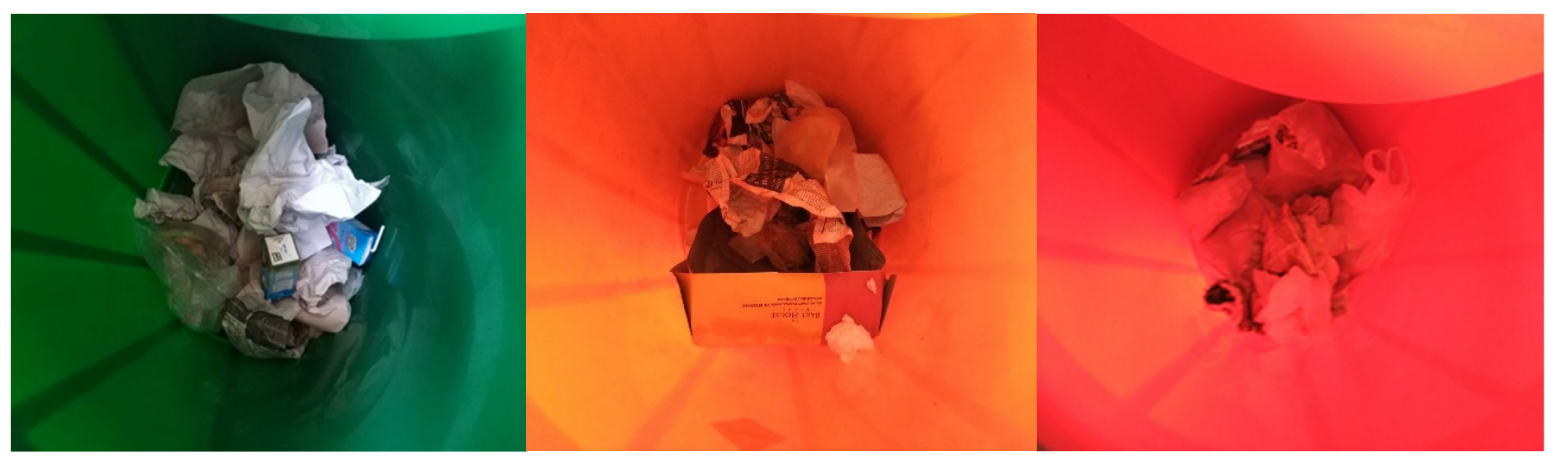

Figure 11. Waste disposal at the baseline

As shown in figure 11, it is clear that the waste sorting practice was not demonstrated at all. We can observe a complete mix of waste and the students were seemed not interested at all in matching the coloured bin with the type of waste expected. Then we need to compare these outcomes with the other two treatments to obtain a clear idea about the expected treatment effects.

\subsubsection{Experimental evidence from treatment 1 [bins with color and name sticker match]}

Treatment 1 of the experiment consisted of three different bins to indicate the expected type of waste and they are labelled with name stickers appropriately. Figure 12 shows the three bins in treatment 1 as follows and then the photographic evidence on the disposed waste for the comparison.
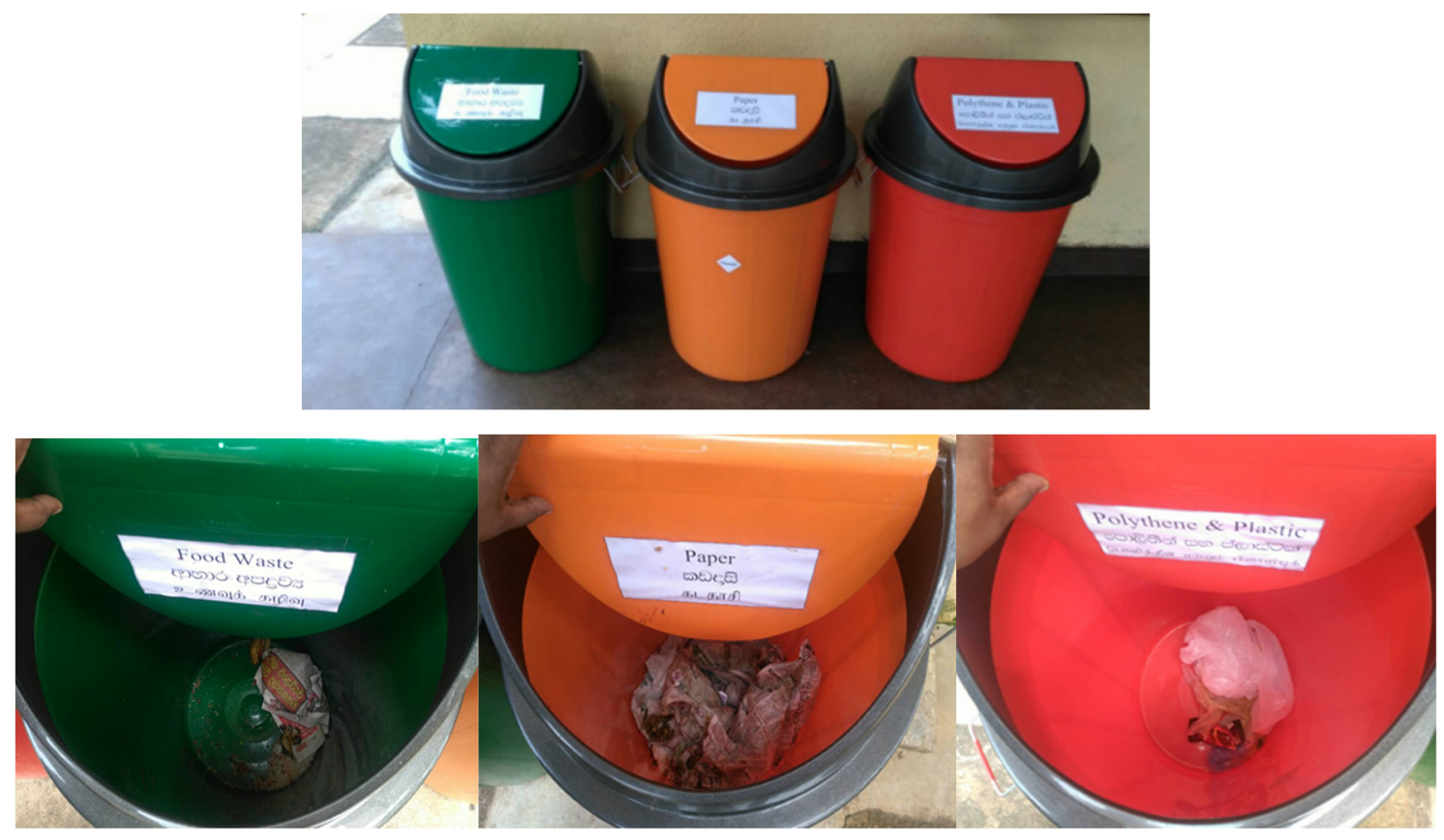

Figure 12. Waste disposal at treatment 1 
As shown in figure 12, photographic evidence shows how the nudge tool motivates the students to sort the waste before disposal. We can observe a clear difference between the student's waste disposal behaviour as the most of waste is disposed of properly through sorting to the appropriate bin. It indicates the degree of impact from the bins placed with a colour and name sticker match. Then we observe the evidence from treatment 3 to gain a clearer idea of the effect of the behavioural nudge.

\subsubsection{Experimental evidence from treatment 2 [bins with color and name sticker mismatch]}

Second treatment of the experiment consisted a mismatch between the colour of bins and the labeled name sticker. Figure 13 shows the three bins in the treatment as follows and then the photographic evidence on the disposed waste for the comparison.
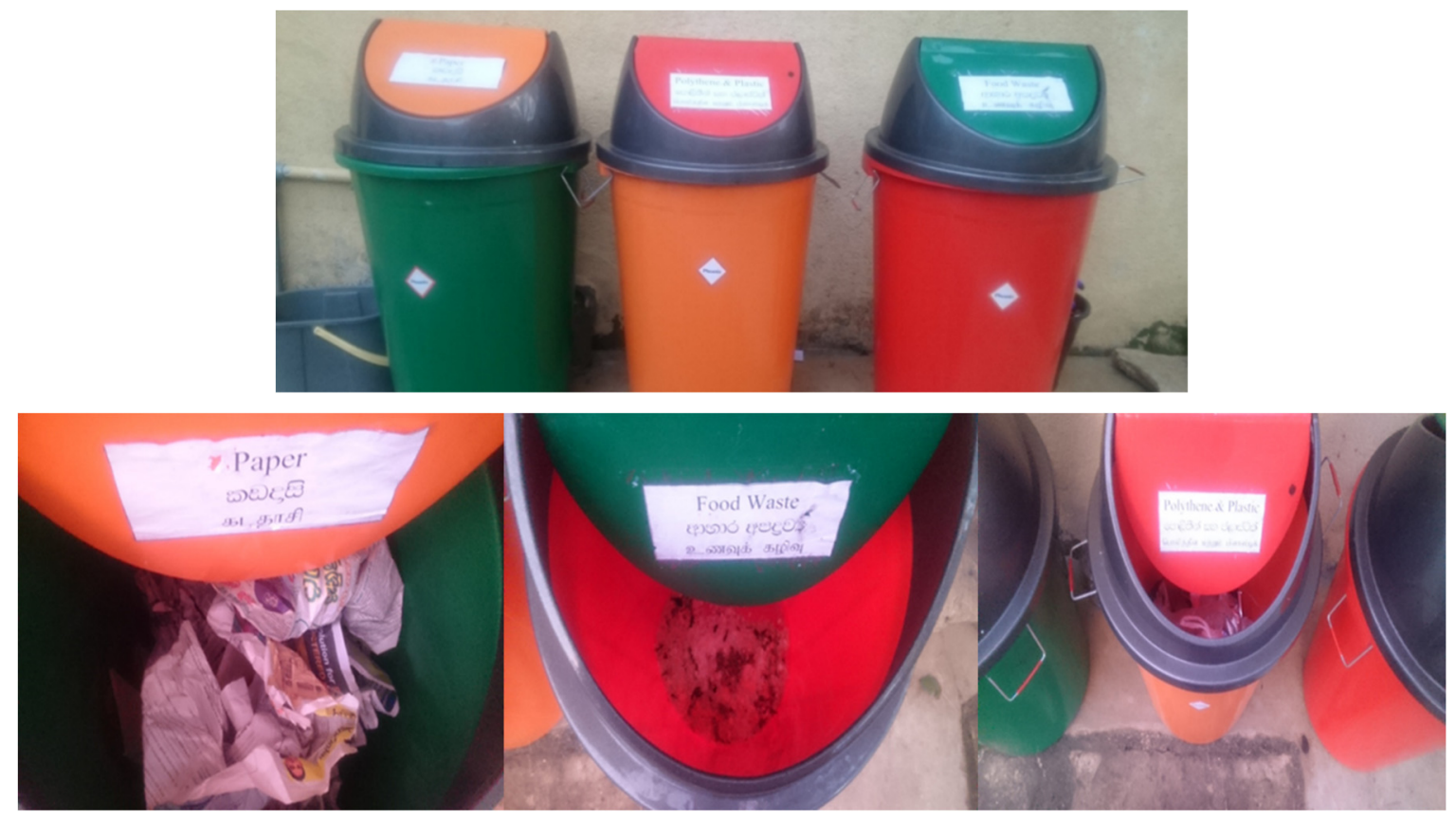

Figure 13. Waste disposal at treatment 2

As shown in figure 13, photographic evidence shows that the colours of the bins [body] are completely messed with its cover and the named sticker. This would generate a significant distraction on the subjects [students] in terms of the impact of colour sensitivity on waste sorting behaviour. However, the evidence shows proper disposal behaviour across the bins though the colour of the bin mismatched the name sticker. It indicates that the named sticker [nudge tool] made a highly significant impact on the waste sorting practice of the individual and it is higher than the expected effect from the colours of the bins on the waste sorting behaviour of the students.

Thus, the comparison of the photographic evidence across the baseline and two treatments can be used to examine the validity of the three hypotheses. Accordingly, the waste sorting behaviour at the first treatment is in a better status when compared to the baseline. This let us accept the first hypothesis [H1] upon the comparison. Then a comparison between the waste sorting behaviours at the baseline and the third treatment implies the validity of the second hypothesis [H2]. Because the waste separation at the second treatment was better than the baseline as the evidence shown. Then the third hypothesis [H3] expects better waste sorting behaviour from the students when compared to the behaviour at the third treatment. However, there is no enough evidence to accept the third hypothesis as the waste sorting practices seem indifferent between the two treatments. Because we observed there was no considerable negative impact from the bin colour mismatch on the sorting behaviour as the name sticker seems not disturbs by the colour mismatch in terms of its strength to motivate the respondents. This verified the opinion by OECD (2017) as multiple behavioural tools may create biases or inefficiencies and affect individual choices on waste sorting.

\section{Discussion}

This study compromise of a framed field survey and a natural experiment to observe the significance of behavioural nudges in improving the accuracy of waste sorting behaviour. The framed field survey indicates the importance of having a novel motivational strategy to enhance the waste sorting practices and use of bins for waste disposal. The 
respondents are very much aware of the importance of waste sorting but not confident about the sorting practices in their actual behaviour. Also, they believed in the significance of non-monetary incentives as a motivational tool to enhance the effectiveness of waste sorting across the citizens. Also, the survey satisfies the findings by Dharmasiri (2020) as the respondent's inefficiency of concurrent waste sorting practices in Sri Lanka. Even the respondents prefer non-monetary incentives and highlighted the importance of innovative motivational strategies described by Ly et al. (2013); Liebig \& Rommel (2014); Helgesen et al. (2015), and Cosic et al. (2018). Accordingly, the respondents are provided with nine behavioural nudge tools and asked to indicate their preferences. Then, the majority of the respondents [ 65 percent] preferred the use of coloured bins with a named sticker as a nudge tool. Then this was used in the natural field experiment to examine the effect of a nudge on the waste sorting behaviour of the respondents via three steps as the baseline and two treatments.

A comparison across the experimental outcomes of the baseline and two treatments expressed the significance of the behavioural nudge in improving the accuracy of waste sorting. The waste sorting behaviour at both treatments is better than the waste sorting at the baseline. Also, this verified the first and second hypotheses. In addition to that, the comparison between the first and second treatments does not demonstrate a significant difference in waste sorting behaviour. This did not provide enough evidence to accept the third hypothesis but indicate how significant the impact of a behavioural nudge on the accuracy of waste sorting behaviour. Thus, the impact of named stickers is highly impactful on the accuracy of waste sorting than the colour sensitivity of the respondents who engaged in the field experiment. Also, the findings highlighted the importance of considering the multiple behavioural biases with the waste sorting and recycling behaviours of individuals (OECD, 2017). This concludes that the bins with named stickers can be identified as a behavioural nudge with a positive impact on the respondents' attitude and accuracy in the waste sorting practices within an internal validity.

Thus, the results revealed the significance of written labels as an effective behavioural nudge to improve the accuracy of waste sorting. Also, these findings matched with Ly et al. (2013), and Cosic et al. (2018) as an innovative behavioural nudge has the potential to improve the waste sorting accuracy of individuals, but the selection of the appropriate nudge tool depends on the characteristics of the population. Then this can be utilized as a strategy within the universities to improve the waste sorting behaviour and then beyond the university community. Also, it is important to perform such surveys and experiments on a larger scale to ensure the external validity of the findings revealed in this study. Further, the other popular nudge tools such as coloured footprints towards the garbage bins can be tested using a similar type of or different community samples.

\section{References}

Achankeng, E. (2003). Globalization, urbanization and municipal solid waste management in Africa. Conference Proceedings-African on a Global Stage, African studies association of Australia and the Pacific (pp.1-22). Retrieved from http://www.wiego.org/sites/default/files/publications/files/Achankeng_Globalization_Urbani zation_MSWMgmt_Africa.pdf.

Aiza, A. N., Agamuthu, A., Fauziah, S. H., \& Khidzir, K. M. (2007). Sustainable waste management - Asian perspectives. Proceedings of the International Conference on Sustainable Solid Waste Management, Chennai, India. (pp.15-26). Retrieved from http://citeseerx.ist.psu.edu/viewdoc/download?doi=10.1.1.533.2785\&rep $=$ rep1\&type $=$ pdf

Alam, P., \& Ahmade, K. (2013). Impact of solid waste on health and the environment. International Journal of Sustainable Development and Green Economics, 2(1), 165-168.

Anamaria, N., Elena J. A., \& Livia, A. A. (n.d.). Nudge - A strategy to increase water consumption. Universitatea "lukion blaga" din sibiu, (pp.01-05).

Ariely, D., Bracha, A., \& Meier, S. (2009). Doing good or doing well? Image motivation and monetary incentives in behaving pro-socially. American Economic Association, 9(1), 544-555. https://doi.org/10.1257/aer.99.1.544

Ayub, S., \& Saleem, Y. (2015). Municipal solid waste dumping practice and its impact assessment. European International Journal of Science and Technology, 4(3), 33-53.

Bandara, N. J. G. J., \& Hettiarachchi, P. J. (2003). Environmental impact associated with current waste disposal practices in a municipality in Sri Lanka. Workshop on a sustainable landfill management, Chennai, India (pp. 19-26). Retrieved from http://citeseerx.ist.psu.edu/viewdoc/download?doi=10.1.1.517.8496\&rep=rep1\&type $=$ pdf

Bandara, N. J. G. J., Gunarathna, G. P. N., \& Liyanage, S. (2010). Analysis of issues and constraints associated with plastic recycling industry in Sri Lanka. Proceedings of the $15^{\text {th }}$ International Forestry and Environment 
Symposium, Department of Forestry and Environmental Science, University of Sri Jayewardenepura, Sri Lanka (pp. 101-107). Retrieved from http://journals.sjp.ac.lk/index.php/fesy mpo/article/view/168/75.

Banuri, S., \& Keefer, P. (2016). Pro-social motivation, effort and the call to public service. European Economic Review, 83, 139-164. https://doi.org/10.1016/j.euro ecorev.2015.10.011.

Brooks, T. (2015). Alcohol and Controlling Risks through Nudges, The New Bioethics, 21(1), 46-55. https://doi.org/10.1179/2050287715Z.00000000064

Carpenter, J., \& Gong, E. (2016). Motivating Agents: How Much Does the Mission Matter? Journal of Labor Economics, 34(1), 211-236. https://doi.org/10.1086/682345

Cooper, E. J. (2017). To nudge or not to nudge: Promoting environmentally beneficial behaviors. Bard Center for Environmental Policy, 10, 01-50. Retrieved from https://digitalcommons.bard.edu /bcep/10.

Cosic, A., Cosic, H., \& Llle, S. (2018). Can nudge affect student's green behaviour? A field experiment. Journal of Behavioral Economics for Policy, 2(1), 107-111.

Dharmasiri, L. M. (2020). Waste Management in Sri Lanka: Challenges and Opportunities. Sri Lanka Journal of Social Sciences, 9(1),72-85.

Durak, S. G. (2016). Investigation and evaluating of the effect to environmental pollution of plastic shopping bag. Turkish Journal of Scientific Reviews, 9(2). 02-24. Retrieved from http://dergipark.gov.tr/derleme/issue/350 98/389376.

Heiskanen, E., Lehner, M., \& Mont, O. (2014). Nudging A Tool for Sustainable behavior? Swedish environmental protection agency.

Helgesen, H., Milford, A. B., \& Ovrum, A. (2015). Nudge to increase recycling and reduce waste. Norwegian Agricultural- Economics Research Institute (01-27). Retrieved from http://nilf.no/publikasjoner/ Discussion_Papers/2015/dp-2015-01.pdf

Herion, O. S., Omran, A., \& Rapp, H. P. (2008). A case study on successful municipal solid waste management industrialized countries by the example of Carlsruhe city, Germany. Journal of Engineering Annals of Faculty of Engineering Hunedoara, 6(3), 266-273.

Hoornweg, D. A., \& Bhada-Tata, P. (2012). What a waste? a global review of solid waste management (English). Urban development series knowledge papers; no. 15. Washington, DC: World Bank Group. Retrieved from http://documents.worldbank.org

Kafando, P. et al. (2013). Environmental impact of waste management deficiencies and health issues: A case study in the city of Kaya, Burkina Faso. Journal of Environmental Protection, 4, 1080-1087. https://doi.org/10.4236/jep.2013.410124

Kanai, R., Kurosawa, R., Matsuda, M., \& Okuyama, M. (2003). Conflict between humans and crows in greater Tokiyo: Garbage management as a possible solution. Global Environmental Research, 7(2), 139-148.

Kroese, F. M., Marchiory, D. R., \& Ridder, D. T. D. D. (2015). Nudging and healthy food choices: A field experiment at the train station. Journal of Public Health, 38(2), 133-137. https://doi.org/10.1093/pubmed/fdv096

Lekammudiyanse, L. M. M. U., \& Gunathilaka, S. K. (2009). Efficiency of the household compost bin as waste management technique in Sri Lanka (A case study in Gampaha municipal council area. International Journal of Basic \& Applied Science, 10(1), 89-94.

Liebig, G., \& Rommel, J. (2014). Active and Forced Choice for Overcoming Status Quo Bias: A Field Experiment on the Adoption of "No junk mail" Stickers in Berlin, Germany. Journal of Consumer Policy, 37(3), 423-435. https://doi.org/10.1007/s10603-014-9264-2

Lokhande, P. A., \& Pawer, M. D. (2016). A review: Garbage collection management system. International Journal of Research in Engineering and Technology, 5(6), 79-82. https://doi.org/10.15623/ijret.2016.0506016

Ly, K. Mazar, N., Zhao, M., \& Soman, D. (2013). A practitioner's guide to nudging. Rotman School of Management Working Paper No 2609347 (pp.01-28). Retrieved from https://papers.ssrn.com/sol3/pape rs.cfm?abstract_id=2609347

Macnabb, L. (2017). "Nudging" environmentally friendly behavior? Experiments on recycling at Uppsla University. Digitala Vetenskapliga Arkivet (pp.01-28). Retrieved from http://www.divaportal.org/smash/ record.jsf?pid $=$ diva2 $\% 3 \mathrm{~A} 1111096 \&$ dswid $=-4187$ 
Makwara, E. C., \& Magudu, S. (2013). Confronting the reckless gambling with people's health and lives: Urban solid waste management in Zimbabwe. European Journal of Sustainable Development, 2(1), 66-98. Retrieved from http://www.ecsdev.org/ojs/index.php/ejsd/article/view/41

Maslow, A. H. (1943). A Theory of human motivation. Psychological Review, 50(4), 370-396. https://doi.org/10.1037/h0054346

Ministry of the Environment. (2012). Solid Waste Management and Recycling Technology of Japan-toward sustainable society. A report produced by the Ministry of the Environment, Japan. Retrieved from https://www.env.go.jp/en/recycle/smcs/attach/swmrt.pdf

OECD. (2017). Using behavioural insights to improve waste management and resource efficiency. In Tackling Environmental Problems with the Help of Behavioural Insights, OECD Publishing, Paris. https://doi.org/10.1787/9789264273887-en

Pardee, R. L. (1990). Motivation theories of Maslow, Herzburg, Mcgregor \& Mclalland. A literature review of selected theories dealing with job satisfaction and motivation. Information analyses: report-general (pp. 0124). Retrieved from https://eric.ed.gov/?id=ED316767

Paz, E. B. (2006). Sustainable sorting, recycling and disposal of solid waste. AU Journal of Technology, 9(3), 133138.

Prendergast, C. (2008). Intrinsic Motivation and Incentives. AEA Papers and Proceedings, 98(2), 201-205. https://doi.org/10.1257/aer.98.2.201

Smith, J. (2016). The Motivational Effects of Mission Matching: A Lab-Experimental Test of a Moderated Mediation Model. Public Administration Review, 76(4), 626-637. https://doi.org/10.1111/puar.12514

Thaler, R. H., \& Sunstein, C. R. (2009). Nudge: Improving decisions about health, wealth and happiness. Penguin.

Themelis, N. J. (2003). An overview of the global waste to energy industry. Waste Management World (pp. 4047). Retrieved from http://www.seas.columbia.edu/earth/papers/global_waste_to_energy.html

UNHSP. (2010). Solid waste management in the world's cities - water and sanitation in the world's cities, Landon, United Nations Sustainable Health Programme (UNSHP). Retrieved from https://thecitywasteproject.files. word press.com

WACS. (2014). Waste Amount and Composition Surveys implemented in the Central and Southern Provinces of Sri Lanka, SATREPS report (May 2014).

WB. (2019). Solid Waste Management. The World Bank Group. September 23, 2019. Retrieved from https://www. worldbank.org/en/topic/urbandevelopment/brief/solid-waste-management

\section{Appendix A}

The Nine Types of Nudges

Nudge 1: Use colored footprints towards the coloured bins.

Nudge 2: Use detailed name stickers or labels with the coloured bins.

Nudge 3: Use of different sounds for different bins.

Nudge 4: Use popular Sri Lankan celebrities for different bins.

Nudge 5: Use the symbols or pictures of different political parties.

Nudge 6: Let people express their views on the existing government by providing different choices for different bins.

Nudge 7: Use different rude or bad characters for different bins.

Nudge 8: Change the shape or size of the bins (i.e., use shapes of animals to redesign bins).

Nudge 9: Prepare the bins similar to a basketball net and let people shoot waste into the bins.

\section{Copyrights}

Copyright for this article is retained by the author(s), with first publication rights granted to the journal.

This is an open-access article distributed under the terms and conditions of the Creative Commons Attribution license (http://creativecommons.org/licenses/by/4.0/). 